\title{
Short-term Outcomes of Robot-assisted Minimally Invasive Esophagectomy Compared With Thoracoscopic or Transthoracic Esophagectomy
}

\author{
EISUKE BOOKA ${ }^{1}$, HIROTOSHI KIKUCHI ${ }^{1}$, RYOMA HANEDA ${ }^{1}$, WATARU SONEDA ${ }^{1}$, \\ SANSHIRO KAWATA $^{1}$, TOMOHIRO MURAKAMI ${ }^{1}$, TOMOHIRO MATSUMOTO ${ }^{1}$, \\ YOSHIHIRO HIRAMATSU ${ }^{1,2}$ and HIROYA TAKEUCHI ${ }^{1}$ \\ ${ }^{1}$ Department of Surgery, Hamamatsu University School of Medicine, Shizuoka, Japan; \\ ${ }^{2}$ Department of Perioperative Functioning Care and Support, \\ Hamamatsu University School of Medicine, Shizuoka, Japan
}

\begin{abstract}
Background/Aim: There is no study comparing open esophagectomy (OE), video-assisted thoracic surgery (VATS), and robot-assisted minimally invasive esophagectomy (RAMIE) in a single institution. Patients and Methods: This study included 272 patients who underwent subtotal esophagectomy divided into three groups: OE $(n=110)$, VATS $(n=127)$, and RAMIE $(n=35)$ groups. Moreover, short-term outcomes were compared. Results: Overall complications $(C D \geq I I)$ were significantly less in the RAMIE than the $O E$ and VATS groups. Recurrent laryngeal nerve paralysis $(C D \geq I I)$ was significantly lower in the RAMIE than the $O E$ group $(p=0.026)$ and tended to be lower than that in the VATS group ( $p=0.059)$. The RAMIE group had significantly less atelectasis $(C D \geq I$ and II), pleural effusion $(C D \geq I$ and II), arrhythmia $(C D \geq I I)$, and dysphagia $(C D \geq I I)$, than both the $O E$ and VATS groups. Conclusion: RAMIE reduced overall postoperative complications after esophagectomy compared with both $O E$ and VATS.
\end{abstract}

Esophageal cancer is the sixth leading cause of cancerrelated mortality worldwide because of its high malignant potential and poor prognosis (1). The postoperative 5-year survival rate in patients with American Joint Committee on

This article is freely accessible online.

Correspondence to: Hiroya Takeuchi, MD, Ph.D., Department of Surgery, Hamamatsu University School of Medicine, 1-20-1 Handayama, Higashi-ku, Hamamatsu, Shizuoka 431-3192, Japan. Tel: +81 534352277, Fax: +81 534352273, e-mail: takeuchi@hamamed.ac.jp

Key Words: Transthoracic esophagectomy, thoracoscopic esophagectomy, robot-assisted minimally invasive esophagectomy.
Cancer stage I esophageal cancer is approximately $90 \%$. This rate decreases to $45 \%, 20 \%$, and $10 \%$ in patients with stages II, III, and IV diseases, respectively (2). Esophagectomy remains the most efficient treatment option, although chemoradiotherapy may effectively treat esophageal cancer (3). Despite advances in extended lymph node (LN) dissection and perioperative management of esophagectomy, it remains a highly invasive procedure associated with serious postoperative complications (4). The Japanese national database, including 5,354 esophagectomy patients in 713 hospitals in 2011, reported an overall morbidity rate of $41.9 \%$ and a 30 -day and surgery-related mortality of $1.2 \%$ and $3.4 \%$, respectively (5).

Thoracoscopic esophagectomy constitutes an attractive and less invasive alternative because esophagectomy with radical lymphadenectomy is one of the most invasive gastrointestinal surgeries (6). Of the patients, 4,209 (66.8\%) underwent video-assisted thoracoscopic surgery (VATS). According to a Japanese national database, the ratio increases annually, including 6,298 esophagectomy patients in 2019 (7). Robot assistance provides an enlarged, threedimensional field of view and improves the surgeon's dexterity due to surgical wrists and tremor filtration (8). Multiple retrospective studies have investigated the surgical outcomes of robot-assisted minimally invasive esophagectomy (RAMIE) compared to VATS since its development in 2003 (9-12). A randomized controlled trial reported the benefits of RAMIE over conventional open esophagectomy (OE) in terms of short-term outcomes, and comparable long-term results to OE were found (13).

However, there is no study comparing the three techniques of OE, VATS, and RAMIE in a single institution. This study hypothesized that VATS reduced postoperative complications compared to OE. Moreover, RAMIE reduced postoperative complications compared to VATS. Therefore, this study 


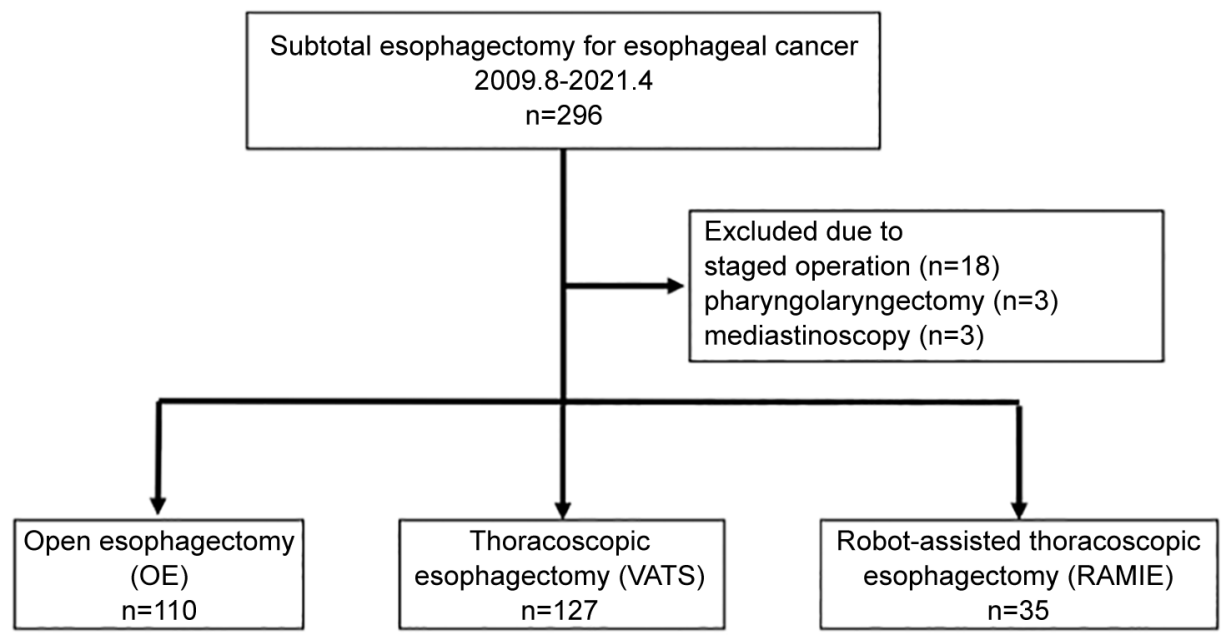

Figure 1. Study design diagram.

investigated the safety, feasibility, and short-term clinical outcomes of RAMIE for esophageal cancer.

\section{Patients and Methods}

Patients. This study retrospectively analyzed the records of 296 patients who underwent subtotal esophagectomy for esophageal cancer at the Department of Surgery, Hamamatsu University School of Medicine, Shizuoka, Japan, between August 2009 and April 2021. Of the 296 patients who underwent subtotal esophagectomy, eighteen who underwent staged operations, three who underwent pharyngolaryngectomy with total esophagectomy and three who underwent mediastinoscopic esophagectomy were excluded. The remaining 272 patients were divided into three groups according to the thoracic approach: OE group $(n=110)$, VATS group $(n=127)$, and RAMIE group ( $n=35$; Figure 1 ). According to the tumor-nodemetastasis (TNM) 8th classification system, all cancers were staged as reported by the International Union against Cancer (14).

Surgical procedure. An epidural cannula was inserted into each patient to administer intraoperative and postoperative analgesia per routine clinical protocol. All surgeries were performed under general anesthesia with selective intubation to block the right lung.

Most operations in the hospital included three-field LN dissection with an anastomosis in the neck (76.1\%). This operation includes a right transthoracic subtotal esophagectomy and dissection of cervical (bilateral supraclavicular region), mediastinal (periesophagus and around the trachea, including the bilateral recurrent laryngeal nerve), and abdominal (perigastric and around the celiac axis) LNs. The other procedures in this study were two-field LN dissection (2FLND) with an anastomosis in the neck (23.9\%). This operation includes a right transthoracic subtotal esophagectomy and dissection of mediastinal and abdominal LNs. All patients underwent LN dissection of the bilateral recurrent laryngeal nerves regardless of the procedures. The anastomosis was hand-sewn in the neck for all cases.

The thoracic procedures were performed through a right thoracic incision in the left decubitus position $(40.4 \%)$ by VATS
$(46.7 \%)$ in the prone or the hybrid position $(15,16)$ or by RAMIE in the prone position (12.9\%). Moreover, RAMIE was performed with the da Vinci Xi system (Intuitive Surgical Inc., Sunnyvale, CA, USA). The trocars for the thoracic RAMIE approach were placed as shown in Figure 2. One 8-mm port was inserted into the ninth or tenth intercostal space (ICS) on the scapular line in RAMIE. Three 8-mm ports were inserted into the seventh, fifth, and third ICSs between the anterior and the posterior axillary lines. Meanwhile, an assistant port was inserted into the fifth ICS on the anterior axillary line. The chest cavity was inflated using carbon dioxide insufflation at an $8-\mathrm{mmHg}$ pressure. The upper mediastinal lymphadenectomy along the bilateral recurrent laryngeal nerves (numbers 106recR and 106recL) was mainly performed using scissors (Figure $3 \mathrm{~A}$ and $\mathrm{B}$ ).

The abdominal procedures were performed through an upper midline abdominal incision $(37.5 \%)$ or by laparoscopic surgery $(62.5 \%)$. Laparoscopic procedures were performed through a minilaparotomy $(9 \mathrm{~cm})$ with five trocars. Each patient was admitted to the intensive care unit (ICU) after surgery, and mechanical ventilation continued overnight. The patients were extubated on postoperative day (POD) 1 and admitted to the general surgical ward on POD 2 if their cardiopulmonary condition was stable.

Morbidity and mortality following esophagectomy. Postoperative complications were categorized using the Clavien-Dindo (CD) classifications as follows (17): grade I was any deviation from the normal postoperative course without the need for pharmacologic treatment or surgical, endoscopic, or radiologic intervention; grade II required pharmacologic treatment with drugs; grade III required surgical, endoscopic, or radiologic intervention; grade IV was lifethreatening complications that required ICU management, and grade V was mortality. Postoperative mortality was defined as expiry within 30 days of operation or mortality during the initial hospitalization.

Statistical analysis. Statistical analysis was performed using IBM SPSS version 27.0 (IBM Corp., Armonk, NY, USA). Demographic and surgical data (pre-, peri-, and postoperative) were compared 


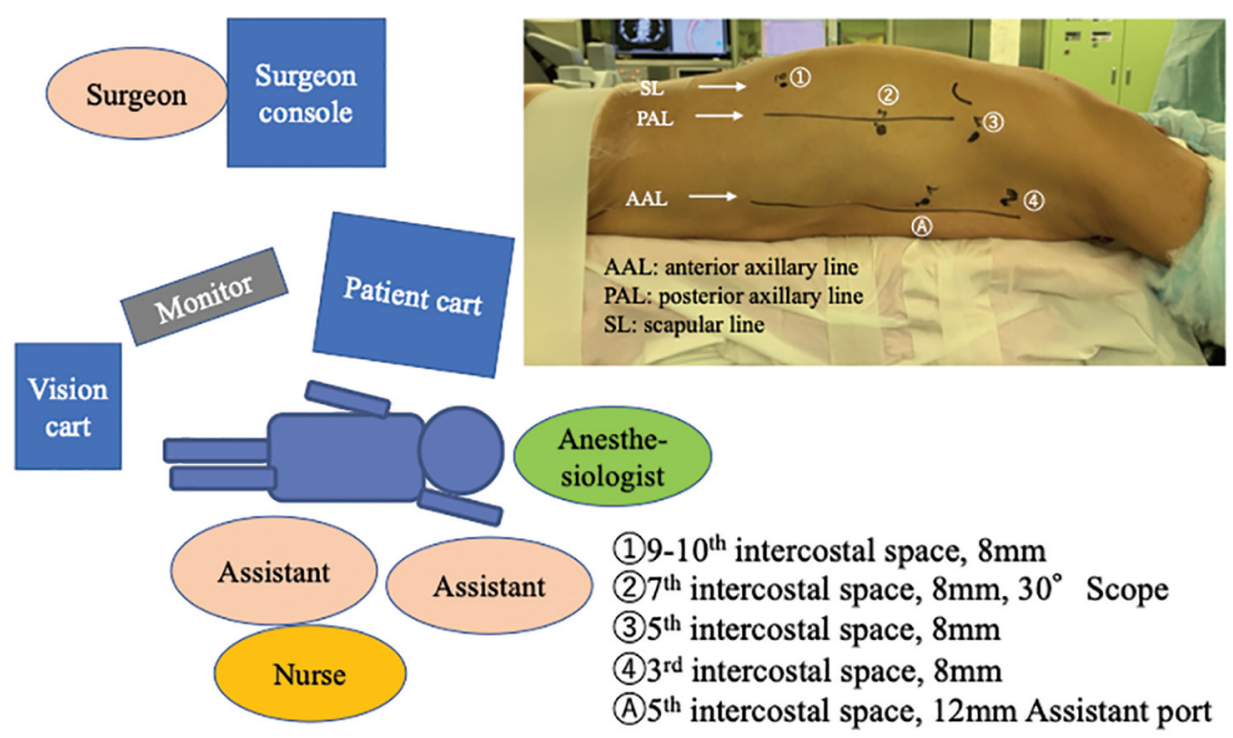

Figure 2. Intraoperative position and port placement for robot-assisted minimally invasive esophagectomy.
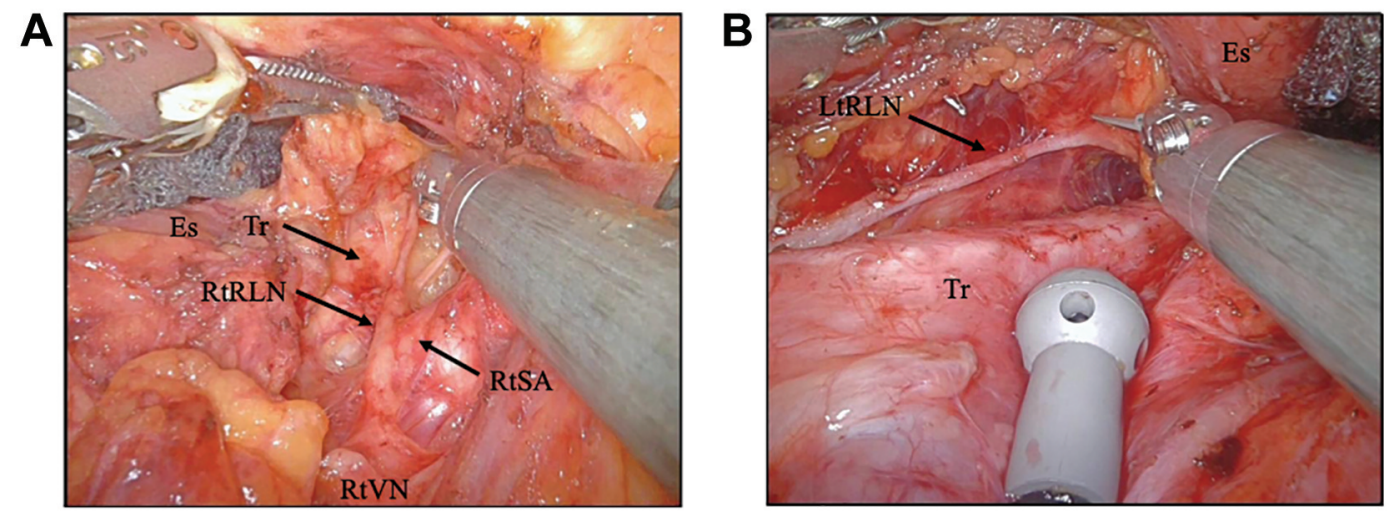

Figure 3. Lymphadenectomy along the right recurrent laryngeal nerve (A) and left recurrent laryngeal nerve (B). Es: Esophagus; Tr: trachea; RtRLN: right recurrent laryngeal nerve; RtSA: right subclavian artery; RtVN: right vagus nerve; LtRLN: left recurrent laryngeal nerve.

between OE and VATSs, OE and RAMIE groups, and VATS and RAMIE groups. Categorical data were analyzed using Fisher's exact test or the chi-square test, as appropriate. Quantitative data were analyzed using unpaired Student's $t$-tests. Moreover, $p<0.05$ was considered statistically significant for all analyses.

\section{Results}

Patient characteristics. Table I shows the clinicopathological characteristics of all patients. The median age was 67 years (range $=32-85$ years). Most patients were male $(87.9 \%)$ and had squamous cell carcinoma $(85.7 \%)$, followed by adenocarcinoma $(12.1 \%)$. All patients in this study had undergone one-stage operations and reconstructed by gastric conduits. The patients were staged using the International
Union against Cancer (UICC 8th edition) TNM classification system (14). According to the clinical staging of the esophageal cancers, 92 (33.8\%), 73 (26.8\%), 99 (36.4\%), and $8(2.9 \%)$ patients were cStages I, II, III, and IV, respectively. The RAMIE group included significantly more 2FLNDs and adenocarcinomas because it had more esophagogastric junction adenocarcinomas. Clinical trials comparing VATS with OE for squamous cell carcinoma (JCOG1409) (18) tended to include nontarget esophagogastric adenocarcinoma in the RAMIE group.

Perioperative outcomes. The intraoperative and postoperative outcomes are shown in Table II. In the OE group, the operation time was shorter, and the amount of blood loss was significantly higher than that in the VATS and 
Table I. Clinicopathological characteristics.

\begin{tabular}{|c|c|c|c|c|c|c|c|}
\hline \multirow[t]{2}{*}{ Characteristics } & \multirow[t]{2}{*}{ All patients } & \multirow[t]{2}{*}{$\mathrm{OE}$} & \multirow[t]{2}{*}{ VATS } & \multirow[t]{2}{*}{ RAMIE } & \multicolumn{3}{|c|}{$p$-Value } \\
\hline & & & & & OE $v s$. VATS & OE $v s$. RAMIE & VATS $v s$. RAMIE \\
\hline Total & 272 & $110(40.4 \%)$ & $127(46.7 \%)$ & $35(12.9 \%)$ & & & \\
\hline Age (years) & $67(32-85)$ & $67(40-79)$ & $68(40-82)$ & $67(32-85)$ & 0.688 & 0.367 & 0.235 \\
\hline Gender & & & & & 0.201 & 0.052 & 0.329 \\
\hline Male & $239(87.9 \%)$ & $101(91.8 \%)$ & $110(86.6 \%)$ & $28(80.0 \%)$ & & & \\
\hline Female & $33(12.1 \%)$ & $9(8.2 \%)$ & $17(13.4 \%)$ & $7(20.0 \%)$ & & & \\
\hline BMI $\left(\mathrm{kg} / \mathrm{m}^{2}\right)$ & $21.4(14.2-33.1)$ & $21.2(14.3-31.2)$ & $21.5(14.2-33.1)$ & $21.3(15.5-28.4)$ & 0.676 & 0.625 & 0.396 \\
\hline ECOG PS & & & & & 0.747 & 0.782 & 0.962 \\
\hline 0 & $210(77.2 \%)$ & $82(74.5 \%)$ & $100(78.7 \%)$ & $28(80.0 \%)$ & & & \\
\hline 1 & $55(20.2 \%)$ & $25(22.7 \%)$ & $24(18.9 \%)$ & $6(17.1 \%)$ & & & \\
\hline 2 & $7(2.6 \%)$ & $3(2.7 \%)$ & $3(2.4 \%)$ & $1(2.9 \%)$ & & & \\
\hline $\begin{array}{l}\text { cStage } \\
\text { (UICC TNM } 8^{\text {th }} \text { ) }\end{array}$ & & & & & $<0.001$ & 0.131 & 0.072 \\
\hline 1 & $92(33.8 \%)$ & $20(18.2 \%)$ & $60(47.2 \%)$ & $12(34.3 \%)$ & & & \\
\hline 2 & $73(26.8 \%)$ & $37(33.6 \%)$ & $30(23.6 \%)$ & $6(17.1 \%)$ & & & \\
\hline 3 & $99(36.4 \%)$ & $48(43.6 \%)$ & $36(28.3 \%)$ & $15(42.9 \%)$ & & & \\
\hline 4 & $8(2.9 \%)$ & $5(4.5 \%)$ & $1(0.8 \%)$ & $2(5.7 \%)$ & & & \\
\hline Surgical procedure & & & & & $<0.001$ & $<0.001$ & 0.008 \\
\hline 3FLND & $207(76.1 \%)$ & $102(92.7 \%)$ & $89(70.1 \%)$ & $16(45.7 \%)$ & & & \\
\hline 2FLND & $65(23.9 \%)$ & $8(7.3 \%)$ & $38(29.9 \%)$ & $19(54.3 \%)$ & & & \\
\hline Reconstructed organ & & & & & 1.000 & 1.000 & 1.000 \\
\hline Gastric conduit & $272(100 \%)$ & $110(100 \%)$ & $127(100 \%)$ & $35(100 \%)$ & & & \\
\hline Others & $0(0 \%)$ & $0(0 \%)$ & $0(0 \%)$ & $0(0 \%)$ & & & \\
\hline Reconstructed route & & & & & 0.980 & 0.557 & 0.617 \\
\hline $\begin{array}{l}\text { Posterior } \\
\text { mediastinal }\end{array}$ & $243(89.3 \%)$ & $97(88.2 \%)$ & $113(89.0 \%)$ & $33(94.3 \%)$ & & & \\
\hline Retrosternal & $27(9.9 \%)$ & $12(10.9 \%)$ & $13(10.2 \%)$ & $2(5.7 \%)$ & & & \\
\hline Antesternal & $2(0.7 \%)$ & $1(0.9 \%)$ & $1(0.8 \%)$ & $0(0 \%)$ & & & \\
\hline Laparotomy & & & & & $<0.001$ & 0.070 & 0.332 \\
\hline Laparoscopy & $170(62.5 \%)$ & $53(48.2 \%)$ & $94(74.0 \%)$ & $23(65.7 \%)$ & & & \\
\hline Open & $102(37.5 \%)$ & $57(51.8 \%)$ & $33(26.0 \%)$ & $12(34.3 \%)$ & & & \\
\hline Tumor location & & & & & 0.074 & 0.131 & 0.823 \\
\hline Ut & $32(11.8 \%)$ & $14(12.7 \%)$ & $15(11.8 \%)$ & $3(8.6 \%)$ & & & \\
\hline Mt & $134(49.3 \%)$ & $63(57.3 \%)$ & $56(44.1 \%)$ & $15(42.9 \%)$ & & & \\
\hline $\mathrm{Lt}$ & $106(39.0 \%)$ & $33(30.0 \%)$ & $56(44.1 \%)$ & $17(48.6 \%)$ & & & \\
\hline Histology & & & & & 0.005 & $<0.001$ & 0.069 \\
\hline $\mathrm{SCC}$ & $233(85.7 \%)$ & $104(94.5 \%)$ & $106(83.5 \%)$ & $23(65.7 \%)$ & & & \\
\hline Adenocarcinoma & $33(12.1 \%)$ & $3(2.7 \%)$ & $19(15.0 \%)$ & $11(31.4 \%)$ & & & \\
\hline Others & $6(2.2 \%)$ & $3(2.7 \%)$ & $2(1.6 \%)$ & $1(2.9 \%)$ & & & \\
\hline $\begin{array}{l}\text { pStage } \\
\left.\text { (UICC TNM } 8^{\text {th }}\right)\end{array}$ & & & & & 0.002 & 0.298 & 0.499 \\
\hline 0 & $10(3.7 \%)$ & $5(4.5 \%)$ & $4(3.1 \%)$ & $1(2.9 \%)$ & & & \\
\hline 1 & $73(26.8 \%)$ & $17(15.5 \%)$ & $45(35.4 \%)$ & $11(31.4 \%)$ & & & \\
\hline 2 & $60(22.1 \%)$ & $25(22.7 \%)$ & $30(23.6 \%)$ & $5(14.3 \%)$ & & & \\
\hline 3 & $88(32.4 \%)$ & $39(35.5 \%)$ & $37(29.1 \%)$ & $12(34.3 \%)$ & & & \\
\hline 4 & $41(15.1 \%)$ & $24(21.8 \%)$ & $11(8.7 \%)$ & $6(17.1 \%)$ & & & \\
\hline
\end{tabular}

Age and BMI are presented as median (range). OE: Open esophagectomy: VATS video-assisted thoracoscopic surgery; RAMIE: robot-assisted minimally invasive esophagectomy; BMI: body mass index; ECOG: Eastern Cooperative Oncology Group; PS: performance status; UICC: International Union against Cancer; TNM: tumor-node-metastasis; FLND: field lymph node dissection; Ut: upper thoracic esophagus (from the superior margin of the sternum to tracheal bifurcation); Mt: middle thoracic esophagus (superior half between tracheal bifurcation and esophagogastric junction); Lt: lower thoracic esophagus (thoracic esophagus from the inferior half between the tracheal bifurcation and esophagogastric junction); SCC: squamous cell carcinoma; 3FLND: three-field lymph node dissection. 
Table II. Intraoperative and postoperative outcomes.

\begin{tabular}{|c|c|c|c|c|c|c|c|}
\hline \multirow[t]{2}{*}{ Characteristics } & \multirow[t]{2}{*}{ All patients } & \multirow[t]{2}{*}{$\mathrm{OE}$} & \multirow[t]{2}{*}{ VATS } & \multirow[t]{2}{*}{ RAMIE } & \multicolumn{3}{|c|}{$p$-Value } \\
\hline & & & & & OE $v s$. VATS & OE $v s$. RAMIE & VATS $v s$. RAMIE \\
\hline Total & 272 & $110(40.4 \%)$ & $127(46.7 \%)$ & $35(12.9 \%)$ & & & \\
\hline $\begin{array}{l}\text { Operation time } \\
\text { (min) }\end{array}$ & $558(318-1,008)$ & $536(318-927)$ & $578(402-1008)$ & $561(455-671)$ & $<0.001$ & 0.440 & 0.014 \\
\hline Blood loss (ml) & $250(10-16,340)$ & $455(80-16,340)$ & $178(10-3,070)$ & $150(30-1,130)$ & 0.003 & 0.062 & 0.345 \\
\hline Mortality & $2(0.7 \%)$ & $2(1.8 \%)$ & $0(0 \%)$ & $0(0 \%)$ & 0.127 & 0.422 & 1.000 \\
\hline $\begin{array}{l}\text { Overall complications } \\
(\mathrm{CD} \geq \mathrm{II})\end{array}$ & is $181(66.5 \%)$ & $77(70.0 \%)$ & $93(73.2 \%)$ & $11(31.4 \%)$ & 0.582 & $<0.001$ & $<0.001$ \\
\hline $\begin{array}{l}\text { Anastomotic } \\
\text { leakage }(\mathrm{CD} \geq \mathrm{II})\end{array}$ & $42(15.4 \%)$ & $22(20.0 \%)$ & $17(13.4 \%)$ & $3(8.6 \%)$ & 0.171 & 0.119 & 0.443 \\
\hline $\operatorname{RLNP}(C D \geq I)$ & $60(22.1 \%)$ & $24(21.8 \%)$ & $32(25.2 \%)$ & $4(11.4 \%)$ & 0.541 & 0.175 & 0.083 \\
\hline RLNP (CD $\geq I I)$ & $26(9.6 \%)$ & $14(12.7 \%)$ & $12(9.4 \%)$ & $0(0 \%)$ & 0.421 & 0.026 & 0.059 \\
\hline $\begin{array}{l}\text { Wound infection } \\
(C D \geq I I)\end{array}$ & $23(8.5 \%)$ & $5(4.5 \%)$ & $16(12.6 \%)$ & $2(5.7 \%)$ & 0.030 & 0.779 & 0.251 \\
\hline Atelectasis $(\mathrm{CD} \geq \mathrm{I})$ & $81(29.8 \%)$ & $33(30.0 \%)$ & $46(36.2 \%)$ & $2(5.7 \%)$ & 0.311 & 0.003 & $<0.001$ \\
\hline Atelectasis $(\mathrm{CD} \geq \mathrm{II})$ & $59(21.7 \%)$ & $29(26.4 \%)$ & $30(23.6 \%)$ & $0(0 \%)$ & 0.626 & 0.001 & 0.001 \\
\hline Pneumonia $(\mathrm{CD} \geq \mathrm{II})$ & $55(20.2 \%)$ & $26(23.6 \%)$ & $24(18.9 \%)$ & $5(14.3 \%)$ & 0.373 & 0.240 & 0.529 \\
\hline $\begin{array}{l}\text { Pleural effusion } \\
(\mathrm{CD} \geq \mathrm{I})\end{array}$ & $128(47.1 \%)$ & $47(42.7 \%)$ & $80(63.0 \%)$ & $1(2.9 \%)$ & 0.002 & $<0.001$ & $<0.001$ \\
\hline $\begin{array}{l}\text { Pleural effusion } \\
(\mathrm{CD} \geq \mathrm{II})\end{array}$ & $85(31.3 \%)$ & $36(32.7 \%)$ & $48(37.8 \%)$ & $1(2.9 \%)$ & 0.416 & $<0.001$ & $<0.001$ \\
\hline Chylothorax (CD $\geq \mathrm{I})$ & $12(4.4 \%)$ & $6(5.5 \%)$ & $6(4.7 \%)$ & $0(0 \%)$ & 0.798 & 0.158 & 0.190 \\
\hline Chylothorax (CD $\geq \mathrm{II})$ & $8(2.9 \%)$ & $3(2.7 \%)$ & $5(3.9 \% \%)$ & $0(0 \%)$ & 0.607 & 0.324 & 0.233 \\
\hline Arrhythmia $(\mathrm{CD} \geq \mathrm{II})$ & $28(10.3 \%)$ & $12(10.9 \%)$ & $16(12.6 \%)$ & $0(0 \%)$ & 0.688 & 0.041 & 0.027 \\
\hline Dysphagia $(\mathrm{CD} \geq \mathrm{II})$ & $67(24.6 \%)$ & $22(20.0 \%)$ & $45(35.4 \%)$ & $0(0 \%)$ & 0.009 & 0.004 & $<0.001$ \\
\hline $\begin{array}{l}\text { Postoperative hospital } \\
\text { stays (days) }\end{array}$ & $25(13-388)$ & $29.5(13-287)$ & $25(14-388)$ & $24(16-104)$ & 0.076 & 0.058 & 0.467 \\
\hline
\end{tabular}

Operation time, blood loss, number of resected mediastinal lymph nodes and postoperative hospital stays are presented as median (range). OE: Open esophagectomy; VATS: video-assisted thoracoscopic surgery; RAMIE: robot-assisted minimally invasive esophagectomy; CD: Clavien-Dindo classification; RLNP: recurrent laryngeal nerve paralysis.

RAMIE groups. Mortality was observed in two patients in the $\mathrm{OE}$ group. However, there was no significant difference. Overall complications $(\mathrm{CD} \geq \mathrm{II})$ were significantly less in RAMIE (31.4\%) compared with OE (70.0\%) and VATS (73.2\%). Recurrent laryngeal nerve paralysis (RLNP; $C D \geq I$ ) occurred in less than half of VATS $(25.2 \%)$ in RAMIE $(11.4 \%)$, although the difference was not significant $(p=0.083)$. RLNP $(\mathrm{CD} \geq \mathrm{II})$ was significantly lower in the RAMIE (0\%) than in the OE $(12.7 \% ; p=0.026)$ group and tended to be lower than in the VATS group $(9.4 \% ; p=0.059)$. The RAMIE group had significantly less atelectasis $(C D \geq I$ and II) and pleural effusion ( $\mathrm{CD} \geq \mathrm{I}$ and II) compared to the $\mathrm{OE}$ and VATS groups. Arrhythmia $(\mathrm{CD} \geq \mathrm{II})$ was significantly lower in the RAMIE $(0 \%)$ than in the OE $(10.9 \% ; p=0.041)$ and VATS $(12.6 \% ; p=0.027)$ groups. Dysphagia $(\mathrm{CD} \geq \mathrm{II})$ was significantly lower in the RAMIE $(0 \%)$ than in the OE $(20.0 \% ; p=0.004)$ and VATS $(35.4 \% ; p<0.001)$ groups. Remarkably, there was no RLNP (CD $\geq \mathrm{II})$, atelectasis $(\mathrm{CD} \geq \mathrm{II})$, chylothorax $(\mathrm{CD} \geq \mathrm{I})$, arrhythmia $(\mathrm{CD} \geq \mathrm{II})$, and dysphagia $(\mathrm{CD} \geq \mathrm{II})$ in the RAMIE group. In the $\mathrm{OE}$ group, postoperative hospital stays (median, 29.5 days) tended to be longer compared with those in the VATS (median, 25 days; $p=0.076$ ) and RAMIE (median, 24 days; $p=0.058$ ) groups. However, the differences were not significant. Comparing the OE with the VATS group, wound infection (CD $\geq \mathrm{II} ; 4.5 \%$ vs. $12.6 \%)$, pleural effusion ( $\mathrm{CD} \geq \mathrm{I} ; 42.7 \%$ vs. $63.0 \%)$, and dysphagia ( $\mathrm{CD} \geq \mathrm{II} ; 20.0 \%$ vs. $35.4 \%)$ in the OE group were significantly less compared with the VATS group.

\section{Discussion}

Several single institution studies have currently demonstrated acceptable short-term outcomes of VATS for thoracic esophageal cancer in terms of operating time, blood loss, and postoperative complications, which are comparable with those of conventional OE $(19,20)$. Regarding operating time, most studies have reported that VATS has a longer operating, and involved less blood loss than OE (20). The current study also significantly demonstrated the longer operation time and less blood loss of VATS than OE. 
Concerning postoperative complications, several studies investigated pulmonary complications, anastomotic leakage, and RLNP (20). Most studies have reported that the incidence of pulmonary complications was lower in VATS than in OE. However, there were no significant differences between VATS and $\mathrm{OE}$ concerning the incidence of anastomotic leakage and RLNP (20). Several studies comparing the short-term outcomes of VATS and OE based on nationwide or prospective data have been recently published (21-25). Those studies reported that the overall rate of surgical complications was higher for VATS than for OE, although VATS was associated with lower rates of respiratory complications than OE. In the current study, VATS did not reduce the incidence of pulmonary complications compared with $\mathrm{OE}$ and did not demonstrate the usefulness over OE.

Only one randomized controlled trial (RCT) regarding RAMIE has been conducted, which compared RAMIE to OE in patients with esophageal cancer (13). This study revealed that RAMIE resulted in a lower percentage of surgery-related overall complications, a better postoperative functional recovery, and similar oncologic outcomes than $\mathrm{OE}$, concluding that RAMIE could improve short-term postoperative outcomes. Some retrospective reports exist according to the RAMIE comparison with VATS $(9-11,26)$. These reports showed only the safety of RAMIE and not its efficacy. Oshikiri et al. recently reported that RAMIE was superior to VATS in the prone position in decreasing left RLNP (27). The current study demonstrated that RAMIE reduced the incidence of overall $(\mathrm{CD} \geq \mathrm{II})$ and pulmonary (atelectasis and pleural effusion) complications, and arrhythmias were significantly compared with both OE and VATS. Compared to OE and VATS, RAMIE had a stronger grip on the esophagus and LNs to be excised. Thus, strongly excluding the lung and heart to gain a good surgical field is not needed. Reducing the strain on the lung and heart may have led to reduced pulmonary complications and arrhythmias. Moreover, VATS has been reported to significantly reduce the incidence of arrhythmias compared to OE (28). However, the current study is the first to report that RAMIE significantly reduced the incidence of arrhythmias compared to OE and VATS. In addition, RLNP $(\mathrm{C}-\mathrm{D} \geq \mathrm{II})$ was significantly lower in RAMIE than in $\mathrm{OE}$ $(p=0.026)$ and tended to be lower than in VATS $(p=0.059)$. Furthermore, the area around the recurrent laryngeal nerve was dissected with scissors to avoid heat damage caused by energy devices in all three procedures. However, RLNP was lower, especially in RAMIE, because it can facilitate magnified three-dimensional imaging and seven degrees of freedom in ambidexterity due to using a manipulator with a wrist and tremor filtration. Therefore, surgeons can accurately perform a procedure and protect the RLN, which must be preserved. Moreover, Otsuka et al. showed that touching or stretching the recurrent laryngeal nerve can be a risk factor for palsy (29). Furthermore, the current study suggested that RAMIE reduced touching or stretching the recurrent laryngeal nerve compared to OE and VATS. These advantages of RAMIE over OE and VATS could also reduce pulmonary complications or arrhythmias.

Remarkably, no dysphagia $(\mathrm{CD} \geq \mathrm{II})$ was noted in the RAMIE group. In addition, dysphagia was significantly lower in the RAMIE than in OE and VATS. Furthermore, RAMIE had less dysphagia because RAMIE had less RLNP than OE and VATS. Dysphagia leads to the deterioration of the swallowing function. Thus, patients with dysphagia had longer postoperative hospital stay. In addition, RAMIE may reduce aspiration pneumonia, because dysphagia can lead to aspiration pneumonia after the start of food intake. Patients with dysphagia had low food intake even after discharge, which led to weight loss. RAMIE has the potential to improve long-term prognosis by preventing weight loss and maintaining postoperative nutritional status. Thus, RAMIE proved useful in various aspects of the current study.

This study is believed to be the first to compare RAMIE with both VATS and OE in a single institution. For the first time, the difference in postoperative complications after esophagectomy between the three groups in a single institution was reported. Postoperative complications did not gradually decrease from OE to VATS and VATS to RAMIE. In an institution where VATS has already reduced postoperative complications compared to OE, RAMIE may not reduce the incidence of postoperative complications compared to VATS. Thus, institutions that did not reduce postoperative complications with the introduction of VATS could benefit from postoperative complication reduction with the introduction of RAMIE.

Postoperative complications were previously reported to significantly negatively impact long-term outcomes after esophagectomy in a single institution study and a metaanalysis (4, 30). Efforts to reduce postoperative complications are mandatory for improving long-term outcomes, suggesting that the introduction of RAMIE may lead to improvement in long-term outcomes.

This study has some limitations, the most important being that it was a retrospective investigation performed at a single institution. Second, the number of patients that underwent RAMIE was small compared with OE and VATS. An external validation study involving a sufficient number of patients is needed to confirm the current study's findings.

In conclusion, RAMIE could reduce postoperative overall and pulmonary complications after esophagectomy compared with OE and VATS. The introduction of RAMIE could lead to the improvement of long-term outcomes.

\section{Conflicts of Interest}

The Authors declare no conflicts of interest in relation to this study. 


\section{Authors' Contributions}

E.B. and H.T. drafted and wrote the manuscript. E.B., H.K., and H.T. were involved in the study design and data interpretation. E.B., R.H., W.S., S.K., T.M., T.M. and Y.H. were involved in data acquisition. E.B. analyzed the data. All Authors read and approved the manuscript.

\section{Acknowledgements}

The Authors thank all the patients and medical staff at the institutions who contributed to this study.

\section{References}

1 Sung H, Ferlay J, Siegel RL, Laversanne M, Soerjomataram I, Jemal A and Bray F: Global cancer statistics 2020: GLOBOCAN estimates of incidence and mortality worldwide for 36 cancers in 185 countries. CA Cancer J Clin 71(3): 209-249, 2021. PMID: 33538338. DOI: $10.3322 /$ caac. 21660

2 Ando N, Ozawa S, Kitagawa Y, Shinozawa Y and Kitajima M: Improvement in the results of surgical treatment of advanced squamous esophageal carcinoma during 15 consecutive years Ann Surg 232(2): 225-232, 2000. PMID: 10903602. DOI: 10.1097/00000658-200008000-00013

3 Cooper JS, Guo MD, Herskovic A, Macdonald JS, Martenson JA Jr, Al-Sarraf M, Byhardt R, Russell AH, Beitler JJ, Spencer S, Asbell SO, Graham MV and Leichman LL: Chemoradiotherapy of locally advanced esophageal cancer: long-term follow-up of a prospective randomized trial (RTOG 85-01). Radiation Therapy Oncology Group. JAMA 281(17): 1623-1627, 1999. PMID: 10235156. DOI: $10.1001 /$ jama.281.17.1623

4 Booka E, Takeuchi H, Nishi T, Matsuda S, Kaburagi T, Fukuda K, Nakamura R, Takahashi T, Wada N, Kawakubo H, Omori T and Kitagawa Y: The impact of postoperative complications on survivals after esophagectomy for esophageal cancer. Medicine (Baltimore) 94(33): e1369, 2015. PMID: 26287423. DOI: 10.1097/MD.0000000000001369

5 Takeuchi H, Miyata H, Gotoh M, Kitagawa Y, Baba H, Kimura W, Tomita N, Nakagoe T, Shimada M, Sugihara K and Mori M: A risk model for esophagectomy using data of 5354 patients included in a Japanese nationwide web-based database. Ann Surg 260(2): 259-266, 2014. PMID: 24743609. DOI: 10.1097/SLA.0000000000000644

6 Takeuchi H, Kawakubo H and Kitagawa Y: Current status of minimally invasive esophagectomy for patients with esophageal cancer. Gen Thorac Cardiovasc Surg 61(9): 513-521, 2013. PMID: 23661109. DOI: 10.1007/s11748-013-0258-9

7 Marubashi S, Takahashi A, Kakeji Y, Hasegawa H, Ueno H, Eguchi S, Endo I, Goi T, Saiura A, Sasaki A and Takiguchi S: Surgical outcomes in gastroenterological surgery in Japan: Report of the National Clinical Database 2011-2019. Ann Gastrointest Surg, 2021. DOI: 10.1002/ags3.12462

8 Kingma BF, de Maat MFG, van der Horst S, van der Sluis PC, Ruurda JP and van Hillegersberg R: Robot-assisted minimally invasive esophagectomy (RAMIE) improves perioperative outcomes: a review. J Thorac Dis 11(Suppl 5): S735-S742, 2019. PMID: 31080652. DOI: 10.21037/jtd.2018.11.104

9 Tagkalos E, Goense L, Hoppe-Lotichius M, Ruurda JP, Babic B, Hadzijusufovic E, Kneist W, van der Sluis PC, Lang H, van
Hillegersberg R and Grimminger PP: Robot-assisted minimally invasive esophagectomy (RAMIE) compared to conventional minimally invasive esophagectomy (MIE) for esophageal cancer: a propensity-matched analysis. Dis Esophagus 33(4): doz060, 2020. PMID: 31206577. DOI: 10.1093/dote/doz060

10 Chen J, Liu Q, Zhang X, Yang H, Tan Z, Lin Y and Fu J: Comparisons of short-term outcomes between robot-assisted and thoraco-laparoscopic esophagectomy with extended two-field lymph node dissection for resectable thoracic esophageal squamous cell carcinoma. J Thorac Dis 11(9): 3874-3880, 2019. PMID: 31656660. DOI: 10.21037/jtd.2019.09.05

$11 \mathrm{He} \mathrm{H}, \mathrm{Wu}$ Q, Wang Z, Zhang Y, Chen N, Fu J and Zhang G: Short-term outcomes of robot-assisted minimally invasive esophagectomy for esophageal cancer: a propensity score matched analysis. J Cardiothorac Surg 13(1): 52, 2018. PMID: 29792203. DOI: 10.1186/s13019-018-0727-4

12 Suda K, Ishida Y, Kawamura Y, Inaba K, Kanaya S, Teramukai S, Satoh $S$ and Uyama I: Robot-assisted thoracoscopic lymphadenectomy along the left recurrent laryngeal nerve for esophageal squamous cell carcinoma in the prone position: technical report and short-term outcomes. World J Surg 36(7): 1608-1616, 2012. PMID: 22392356. DOI: 10.1007/s00268-012-1538-8

13 van der Sluis PC, van der Horst S, May AM, Schippers C, Brosens LAA, Joore HCA, Kroese CC, Haj Mohammad N, Mook S, Vleggaar FP, Borel Rinkes IHM, Ruurda JP and van Hillegersberg R: Robot-assisted minimally invasive thoracolaparoscopic esophagectomy versus open transthoracic esophagectomy for resectable esophageal cancer: a randomized controlled trial. Ann Surg 269(4): 621-630, 2019. PMID: 30308612. DOI: $10.1097 /$ SLA.0000000000003031

14 Brierley JD, Gospodarowicz MK and Wittekind C: TNM classification of malignant tumors: International union against cancer. $8^{\text {th }}$ ed. Oxford, Wiley, 2017.

15 Kaburagi T, Takeuchi H, Kawakubo H, Omori T, Ozawa S and Kitagawa Y: Clinical utility of a novel hybrid position combining the left lateral decubitus and prone positions during thoracoscopic esophagectomy. World J Surg 38(2): 410-418, 2014. PMID: 24101023. DOI: 10.1007/s00268-013-2258-4

16 Kikuchi H, Hiramatsu Y, Matsumoto T, Soneda W, Kawata S, Hirotsu A, Kamiya K and Takeuchi H: The hybrid position is superior to the prone position for thoracoscopic esophagectomy with upper mediastinal lymphadenectomy. Annals of Laparoscopic and Endoscopic Surgery 5: 13-13, 2020. DOI: 10.21037/ales.2020.03.05

17 Dindo D, Demartines N and Clavien PA: Classification of surgical complications: a new proposal with evaluation in a cohort of 6336 patients and results of a survey. Ann Surg 240(2): 205-213, 2004. PMID: 15273542. DOI: 10.1097/01.sla. 0000133083.54934.ae

18 Kataoka K, Takeuchi H, Mizusawa J, Ando M, Tsubosa Y, Koyanagi K, Daiko H, Matsuda S, Nakamura K, Kato K, Kitagawa Y and Japan Esophageal Oncology Group/Japan Clinical Oncology Group: A randomized Phase III trial of thoracoscopic versus open esophagectomy for thoracic esophageal cancer: Japan Clinical Oncology Group Study JCOG1409. Jpn J Clin Oncol 46(2): 174177, 2016. PMID: 26732383. DOI: 10.1093/jjco/hyv178

19 Watanabe M, Baba Y, Nagai Y and Baba H: Minimally invasive esophagectomy for esophageal cancer: an updated review. Surg Today 43(3): 237-244, 2013. PMID: 22926551. DOI: 10.1007/ s00595-012-0300-z 
20 Booka E, Takeuchi H, Kikuchi H, Hiramatsu Y, Kamiya K, Kawakubo H and Kitagawa Y: Recent advances in thoracoscopic esophagectomy for esophageal cancer. Asian J Endosc Surg 12(1): 19-29, 2019. PMID: 30590876. DOI: 10.1111/ases.12681

21 Takeuchi H, Miyata H, Ozawa S, Udagawa H, Osugi H, Matsubara H, Konno H, Seto Y and Kitagawa Y: Comparison of short-term outcomes between open and minimally invasive esophagectomy for esophageal cancer using a nationwide database in Japan. Ann Surg Oncol 24(7): 1821-1827, 2017. PMID: 28224366. DOI: 10.1245/s10434-017-5808-4

22 Biere SS, van Berge Henegouwen MI, Maas KW, Bonavina L, Rosman C, Garcia JR, Gisbertz SS, Klinkenbijl JH, Hollmann MW, de Lange ES, Bonjer HJ, van der Peet DL and Cuesta MA: Minimally invasive versus open oesophagectomy for patients with oesophageal cancer: a multicentre, open-label, randomised controlled trial. Lancet 379(9829): 1887-1892, 2012. PMID: 22552194. DOI: 10.1016/S0140-6736(12)60516-9

23 Mamidanna R, Bottle A, Aylin P, Faiz O and Hanna GB: Shortterm outcomes following open versus minimally invasive esophagectomy for cancer in England: a population-based national study. Ann Surg 255(2): 197-203, 2012. PMID: 22173202. DOI: 10.1097/SLA.0b013e31823e39fa

24 Nozaki I, Mizusawa J, Kato K, Igaki H, Ito Y, Daiko H, Yano M, Udagawa H, Nakagawa S, Takagi M and Kitagawa Y: Impact of laparoscopy on the prevention of pulmonary complications after thoracoscopic esophagectomy using data from JCOG0502: a prospective multicenter study. Surg Endosc 32(2): 651-659, 2018. PMID: 28779246. DOI: 10.1007/s00464-017-5716-5

25 Seesing MFJ, Gisbertz SS, Goense L, van Hillegersberg R, Kroon HM, Lagarde SM, Ruurda JP, Slaman AE, van Berge Henegouwen MI and Wijnhoven BPL: A propensity score matched analysis of open versus minimally invasive transthoracic esophagectomy in the Netherlands. Ann Surg 266(5): 839-846, 2017. PMID: 28796016. DOI: 10.1097/SLA. 0000000000002393
26 Gong L, Jiang H, Yue J, Duan X, Tang P, Ren P, Zhao X, Liu X, Zhang $\mathrm{X}$ and $\mathrm{Yu} \mathrm{Z}$ : Comparison of the short-term outcomes of robot-assisted minimally invasive, video-assisted minimally invasive, and open esophagectomy. J Thorac Dis 12(3): 916-924, 2020. PMID: 32274159. DOI: 10.21037/jtd.2019.12.56

27 Oshikiri T, Goto H, Horikawa M, Urakawa N, Hasegawa H, Kanaji S, Yamashita K, Matsuda T, Nakamura T and Kakeji Y: Incidence of recurrent laryngeal nerve palsy in robot-assisted versus conventional minimally invasive McKeown esophagectomy in prone position: A propensity score-matched study. Ann Surg Oncol, 2021. PMID: 34032960. DOI: 10.1245/s10434-021-10123-w

28 Chen L, Zhang L, Shi L, Fu G and Jiang C: The role of surgery type in postoperative atrial fibrillation and in-hospital mortality in esophageal cancer patients with preserved left ventricular ejection fraction. World J Surg Oncol 18(1): 244, 2020. PMID: 32917215. DOI: 10.1186/s12957-020-02011-6

29 Otsuka K, Murakami M, Goto S, Ariyoshi T, Yamashita T, Saito A, Kohmoto M, Kato R, Lefor AK and Aoki T: Minimally invasive esophagectomy and radical lymph node dissection without recurrent laryngeal nerve paralysis. Surg Endosc 34(6): 2749-2757, 2020. PMID: 32016515. DOI: 10.1007/s00464-02007372-3

30 Booka E, Takeuchi H, Suda K, Fukuda K, Nakamura R, Wada N, Kawakubo H and Kitagawa Y: Meta-analysis of the impact of postoperative complications on survival after oesophagectomy for cancer. BJS Open 2(5): 276-284, 2018. PMID: 30263978. DOI: $10.1002 /$ bjs5.64 